\title{
Mental health in Northern Ireland: have "the Troubles" made it worse?
}

\section{O'Reilly, M Stevenson}

See end of article for authors' affiliations

.......................

Correspondence to: Dr D O'Reilly, Department of Epidemiology and Public Health, Mulhouse Building, Royal Group of Hospitals, Grosvenor Road, Belfast BT12 6BJ, Northern Ireland;

d.oreilly@qub.ac.uk

Accepted for publication 27 November 2002

\begin{abstract}
Objectives: To measure the effects of the civil unrest (the Troubles) on the mental health of the general population of Northern Ireland.

Design: A secondary analysis of a nationally representative population survey conducted in 1997. Setting: Northern Ireland.

Methods: This is an analysis of the 1694 respondents (aged 16-64) who had their mental health assessed using the 12 question version of the General Health Questionnaire (GHQ). The effects of the Troubles was based on the responses to two survey questions; one asking about the impact on respondent's area; the second about the impact on the life of the respondent or their family. To model simultaneous effects, multiple logistic regression models were constructed with GHQ case as the dependent variable, the impact of the Troubles questions as independent variables, and the demographic, socioeconomic, and health related factors as covariates.

Results: $21.3 \%$ (361) of respondents said that the Troubles had either "quite a bit" or "a lot" of impact on their lives or the lives of their families and $25.1 \%(418)$ reported a similar impact on their area of residence. The likelihood of psychological morbidity increased the greater the extent to which the Troubles affected the respondent's area or life, the association being stronger for the second factor. Neither demographic nor socioeconomic factors significantly diminished this relation although adjusting for health related factors did attenuate the magnitude of the odd ratios especially for the effects of the Troubles on area of residence.

Conclusion: It is probable that mental health of the population of Northern Ireland has been significantly affected by the Troubles. Whether this is attributable to the violence in itself or to other aspects of the Troubles is unclear and whether any additional inputs from psychiatric services are needed requires further study.
\end{abstract}

$\mathrm{R}$ ecent comparisons of mental health status in Northern Ireland and other countries in the British Isles (using an abridged version of the well validated General Health Questionnaire (GHQ, ${ }^{1}$ the GHQ12), show that the level of psychiatric morbidity in Northern Ireland is higher than in either Scotland or England ${ }^{2}$ and much higher than those in the Republic of Ireland. ${ }^{3}$ The reasons for these variations in mental health status are not known.

One obvious difference between these countries is the civil disturbance or unrest, known colloquially as "the Troubles" that the people of Northern Ireland have endured for the past 30 years. During this time more than 3600 people have been killed $^{4}$ and thousands more injured or traumatised. Yet over the years there has been comparatively little study of the impact of the Troubles on the health of the public. ${ }^{6}$ The evidence regarding an effect on mental health is ambiguous, as some researchers have argued that there are visible and marked effects of exposure to the violence ${ }^{7}$ while others have suggested a rapid improvement among those exposed to traumatic events indicating a lesser impact. ${ }^{8}$ Most studies have however, focused on selected subpopulations in Northern Ireland such as children ${ }^{9}$ or possible litigants ${ }^{10}{ }^{11}$ rather than the wider population and/or have poorly controlled for potential confounding influences such as socioeconomic or physical health status. Other studies have shown that the level of depression among 11-15 year old secondary school students in Northern Ireland is higher than recorded in other "normal" populations ${ }^{12}$ though the extent to which this is attributable to the politically unsettled nature of Northern Irish society is unclear as participants had not been asked about their experience of the Troubles. ${ }^{13}$
This study aims to examine the effects of the Troubles on the general population while controlling for a much greater array of potential confounding factors than was possible in previous studies. The study is based on the premise that if the Troubles have a tangible effect on mental health then those people who had experienced a greater exposure to the Troubles, either directly on their lives or by virtue of where they live should, all other things being equal, exhibit higher levels of psychological morbidity.

\section{METHODS}

This is a secondary analysis of data collected as part of the Northern Ireland Health and Wellbeing Survey (1997), which was based on a random sample of households throughout the country, stratified by health board. The response rate was 75\% and a total of 4688 people were interviewed. To reduce the overall burden on respondents only a subset of respondents $(n=2093,51 \%)$ was asked to complete the GHQ12. These people were selected during the interview process by the computer used to record the survey responses, which generated a random number. The results presented in this paper relate only to those 1694 respondents aged between 16 and 64-that is, the same age range as used for most of the international comparisons.

The respondent characteristics used in these analyses related to those demographic, socioeconomic, and health related factors that are known to be related to mental health status. ${ }^{14}{ }^{15}$ Religious affiliation was included as an additional social characteristic as there are recognised socioeconomic and physical health differences between the two dominant (Roman Catholic and Protestant) communities. ${ }^{16}{ }^{17}$ Car availability, tenure (dichotomised into renting, not renting), and 
household income (adjusted to allow for different numbers and ages of dependants ${ }^{18}$ ) were used to characterise socioeconomic standing. The presence of a limiting long term illness or any disability (ranging from the inability to walk 200 metres without difficulty, to being bed or house bound) was also captured. Health related factors, which are substantially related to mental health status, were not included in the analysis as this would have been tautological. The presence of any health stressor in the preceding year (such as an operation or the worsening of a clinical condition, the death of friend or family member, etc) was also included, as was the amount of perceived social support (assessed as in the Health and Lifestyle Survey ${ }^{19}$ and the scores categorised into "no lack", "some lack", and "a severe lack" of support).

The GHQ12 was self completed by the respondent. High scores represent poorer mental health and a cut off is often chosen to indicate significant psychological morbidity (that is, GHQ caseness, corresponding to the average case referred to a psychiatrist), ${ }^{1}$ though there is no consensus as to what this threshold should be. In this paper a threshold score of 3 or more was chosen as a compromise between the need to maximise selectivity while at the same time providing sufficient cases for analysis. A subsequent check of the models was undertaken using a cut off of 4 or more. The exposure to the Troubles was based on the responses to two survey questions (box 1); one asking about the impact " . . .on your area"; the second about the impact "... on you or your family's life". Four ordered response categories ranging from "not very much at all" to "a lot" were possible.

All data were analysed in SPSS. The analytical strategy was in two parts. In the first instance we attempted to see if the
Box 1 Survey questions to assess the effect of the

Troubles

1 Effects on area

I'd like to ask you a few questions about the effects of the Troubles have had. Things change from time to time but, thinking about the whole period since 1969, how much violence would you say there has been in this area because of the Troubles?

- not very much at all

- Just a bit

- Quite a bit

- A lot

\section{Effect on life}

How much have the Troubles affected your own life and the lives of your immediate family?

- not very much at all

- Just a bit

- Quite a bit

- A lot

relation between the Troubles and mental health could be accounted for by other characteristics of the respondents. A series of logistic regression models were therefore constructed entering in turn the demographic, socioeconomic, and health related factors in blocks to see if these reduced the likelihood of poor mental health in people whose areas or lives had been affected by the Troubles. These analyses were undertaken separately for the area and life effects of the Troubles. A final logistic regression analysis was undertaken with responses to

Table 1 (A) The effects of the Troubles on respondent's area of residence: demographic, socioeconomic, and health characteristics and (B) The effects of the Troubles on respondent's (or family's) life: demographic, socioeconomic, and health characteristics

\begin{tabular}{|c|c|c|c|c|c|}
\hline & \multicolumn{4}{|c|}{ (A) The effects of the Troubles on respondent's area of residence } & \multirow[b]{2}{*}{$\mathrm{p}$ Value } \\
\hline & $\begin{array}{l}\text { Not very } \\
\text { much at all }\end{array}$ & Just a little & Quite a bit & A lot & \\
\hline \multicolumn{6}{|l|}{ Demographic factors } \\
\hline $\begin{array}{l}\text { Number of respondents } \\
\text { Mean age years (SD) }\end{array}$ & $\begin{array}{l}824 \\
39.3(13.7)\end{array}$ & $\begin{array}{l}434 \\
37.8 \text { (13.9) }\end{array}$ & $\begin{array}{l}298 \\
36.7(14.1)\end{array}$ & $37.8(13.3)$ & 0.02 \\
\hline$\%$ Catholic & 47.3 & 46.6 & 55.9 & 67.2 & $<0.01$ \\
\hline \multicolumn{6}{|l|}{ Socioeconomic factors } \\
\hline$\%$ Without access to a car & 13.0 & 17.1 & 31.6 & 42.4 & $<0.001$ \\
\hline$\%$ Renting accommodation & 20.5 & 26.7 & 43.4 & 43.2 & $<0.001$ \\
\hline Mean income $(S D)^{*}$ & $14.4(9.2)$ & $13.8(8.7)$ & $12.1(7.7)$ & $11.4(7.9)$ & $<0.001$ \\
\hline \multicolumn{6}{|l|}{ Health factors } \\
\hline Limiting long term illness & 18.5 & 19.1 & 21.5 & 39.0 & $<0.001$ \\
\hline Disability & 6.9 & 6.7 & 9.4 & 18.6 & $<0.01$ \\
\hline Health stressors & 13.4 & 12.0 & 17.6 & 23.7 & $<0.01$ \\
\hline Lack of social support & 17.0 & 18.0 & 12.1 & 22.9 & 0.72 \\
\hline
\end{tabular}

(B) The effects of the Troubles on respondent's (or family's) life

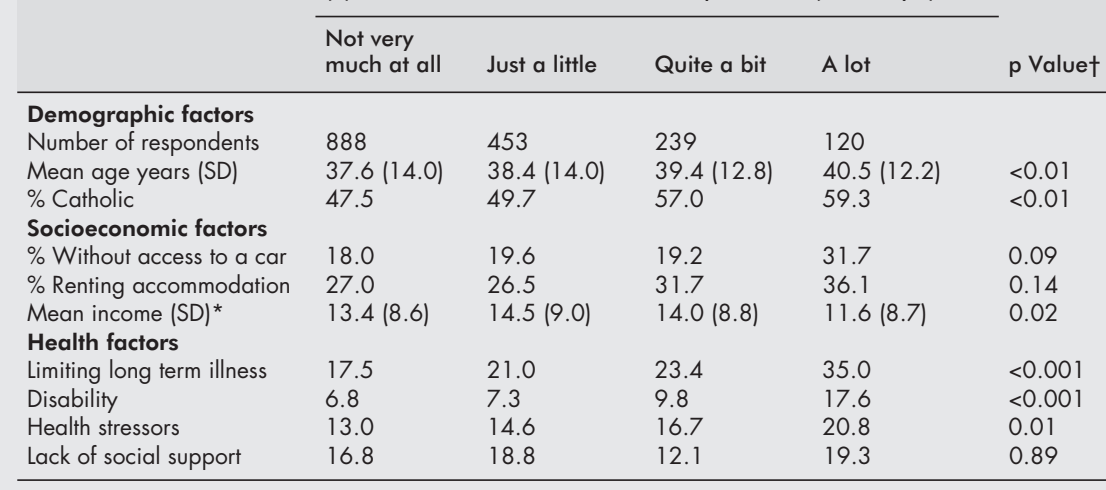

${ }^{*}$ Income is in euros (000s). †Based on $\chi^{2}$ test for trend for categorical variables and on analysis of variance for continuous variables. 
Table 2 GHQ12 scores and caseness according to the effects of the Troubles on respondent's area or life

\begin{tabular}{|c|c|c|c|c|c|}
\hline & $\begin{array}{l}\text { Not very } \\
\text { much at all }\end{array}$ & Just a little & Quite a bit & A lot & $\mathrm{p}$ Value \\
\hline \multicolumn{6}{|l|}{ Area effects } \\
\hline Number of respondents & 824 & 434 & 298 & 118 & \\
\hline Mean GHQ12 score (SD) & $1.87(3.08)$ & $1.92(2.83)$ & $2.65(3.26)$ & $4.12(4.02)$ & $<0.001$ \\
\hline$\% \mathrm{GHQ}$ case & 24.6 & 27.9 & 38.3 & 52.1 & $<0.001$ \\
\hline \multicolumn{6}{|l|}{ Effects on life } \\
\hline Number of respondents & 888 & 453 & 239 & 120 & \\
\hline Mean GHQ12 score (SD) & $1.86(2.98)$ & $2.18(3.05)$ & $2.62(3.32)$ & $3.85(4.14)$ & $<0.001$ \\
\hline$\%$ GHQ case* & 24.6 & 27.9 & 37.2 & 47.1 & $<0.001$ \\
\hline
\end{tabular}

both impact of the Troubles questions entered as independent variables and the demographic, socioeconomic, and health related factors as potential covariates. Only those variables shown in the univariate analysis to be significantly related to the GHQ12 case $($ at $p<0.1)$ were entered into the final regression model. The data shown in tables 1 and 2 were reweighted to show the distributions of the various indicators at a Northern Ireland level. The logistic regression analyses were performed on the unweighted data.

\section{RESULTS}

In this study $21.3 \%$ (361) of the respondents said that the Troubles had either "quite a bit" or "a lot" of impact on their lives or the lives of their families and $25.1 \%$ (418) reported a similar impact on their area of residence. There was only a relatively modest agreement between these two measures of the effect of the Troubles (weighted $\kappa=0.28, \mathrm{p}<0.001$ ). Respondents who said that areas in which they lived were more affected by the Troubles tended to be Catholic and were more likely to have lower incomes, to live in rented accommodation, and to have poorer health (table lA). Those people whose lives were most affected by the Troubles also tended to be Catholic and to have a higher prevalence of ill health though they tended to be older and the association with socioeconomic status was less clear cut (table 1B).

There were $578(27.6 \%)$ of the respondents with a GHQ score of 3 or more and $445(21.3 \%)$ with a score of 4 or more. Univariate analysis demonstrated the usual associations between demographic and social factors and poor mental health. Women and those who were separated, widowed, or divorced were more likely (than men or married people) to have significant psychological morbidity and there was a clear association with low socioeconomic status and poorer physical health. While Catholics tended to have higher GHQ scores than Protestants, this did not reach statistical significance at the 0.05 level. Both the GHQ12 score and the prevalence of significant psychological morbidity (as defined as having a GHQ12 score of three or more) were significantly related in a step wise fashion to the extent to which the Troubles had an impact on both the respondent's lives and the areas in which they lived (table 2).

Table 3 shows the odds ratios for the association between the Troubles and the presence of significant psychological ill health before and after adjustment for potential confounding variables. The greater the extent to which the respondent's area or life was affected by the Troubles, the greater the likelihood that the respondent had poorer mental health. Neither demographic nor socioeconomic factors significantly diminished this relation although it was attenuated after adjusting for health related factors.

The final logistic regression model, in which the effects of the Troubles both on area of residence and on lives are included, is shown in table 4. There was no significant age related gradient in the prevalence of psychological ill health within this age range and the associations between psychological ill health and socioeconomic status became nonsignificant after the inclusion of health related factors. Women

Table 3 Logistic regression: GHQ12 case as dependent variable, effects of the Troubles as independent variables, with and without adjustment for possible demographic, socioeconomic, and health related confounders

\begin{tabular}{|c|c|c|c|c|c|}
\hline & \multicolumn{4}{|c|}{$\begin{array}{l}\text { Effects of the Troubles on respondent area } \\
\text { Odds ratios ( } 95 \% \text { confidence intervals) }\end{array}$} & \multirow[b]{2}{*}{$\mathrm{p}$ Value } \\
\hline & $\begin{array}{l}\text { Not very } \\
\text { much at all }\end{array}$ & Just a little & Quite a bit & A lot & \\
\hline Model 1 & 1.00 & 1.12 (0.86 to 1.47$)$ & 1.71 (1.29 to 2.27 ) & 2.62 (1.76 to 3.90$)$ & $<0.001$ \\
\hline Model 2 & 1.00 & $1.18(0.90$ to 1.55$)$ & 1.70 (1.27 to 2.28 ) & 2.53 (1.68 to 3.83$)$ & $<0.001$ \\
\hline Model 3 & 1.00 & $1.16(0.88$ to 1.52$)$ & 1.62 (1.21 to 2.18$)$ & 2.43 (1.60 to 3.68$)$ & $<0.001$ \\
\hline \multirow[t]{3}{*}{ Model 4} & 1.00 & $1.18(0.88$ to 1.58$)$ & 1.70 (1.24 to 2.32$)$ & 1.92 (1.23 to 3.00$)$ & 0.001 \\
\hline & \multicolumn{4}{|c|}{$\begin{array}{l}\text { Effects of the Troubles on respondent or families life } \\
\text { Odds ratios ( } 95 \% \text { confidence intervals) }\end{array}$} & \\
\hline & $\begin{array}{l}\text { Not very } \\
\text { much at all }\end{array}$ & Just a little & Quite a bit & A lot & $\mathrm{p}$ Value \\
\hline Model 1 & 1.00 & 1.50 (1.16 to & $2.18(1.61$ & $2.50 \quad(1.6$ & $<0.001$ \\
\hline Model 2 & 1.00 & 1.52 (1.17 to 1.97$)$ & 2.11 (1.55 to 2.88 ) & 2.35 (1.57 to 3.52 ) & $<0.001$ \\
\hline Model 3 & 1.00 & 1.52 (1.17 to 1.98$)$ & 2.11 (1.55 to 2.87$)$ & 2.30 (1.54 to 3.45$)$ & $<0.001$ \\
\hline Model 4 & 1.00 & $1.48(1.12$ to 1.96$)$ & 2.07 (1.49 to 2.88 ) & 1.91 (1.24 to 2.96$)$ & $<0.001$ \\
\hline
\end{tabular}

Model 1 Effect of Troubles on mental health (unadjusted). Model 2 Model 1 adjusted for age, sex, martial status, and religion. Model 3 Model 2 adjusted for car availability, tenure, and household income. Model 4 Model 3 adjusted for LLTI, disability, health stresses, and perceived social support. 
Table 4 Final regression model with GHQ12 case as dependent and with both the effects of the Troubles on respondent's area and life entered as covariates

\begin{tabular}{|c|c|c|}
\hline & Odds ratio $(95 \% \mathrm{Cl})$ & $\mathrm{p}$ Value \\
\hline Sex (female $v$ male) & $1.93(1.5$ to 2.48$)$ & $<0.001$ \\
\hline \multicolumn{3}{|l|}{ Marital status } \\
\hline Married/cohabiting & 1.00 & 0.024 \\
\hline Single & $1.14(0.87$ to 1.50$)$ & 0.338 \\
\hline Widowed/separated/divorced & $1.69(1.16$ to 2.48$)$ & 0.007 \\
\hline Limiting long term illness (yes $v$ no) & $2.12(1.55$ to 2.91$)$ & $<0.001$ \\
\hline Disability (any $v$ none) & $3.88(2.42$ to 6.21$)$ & $<0.001$ \\
\hline Health stress (any $v$ none) & $1.82(1.31$ to 2.54$)$ & $<0.001$ \\
\hline Lacking social support (yes $v$ no) & $2.06(1.53$ to 2.78$)$ & $<0.001$ \\
\hline \multicolumn{3}{|l|}{ Troubles affecting life } \\
\hline Not very much at all & 1.00 & $<0.01$ \\
\hline Just a little & 1.40 (1.05 to 1.87$)$ & $<0.01$ \\
\hline Quite a bit & $1.83(1.30$ to 2.58$)$ & 0.001 \\
\hline A lot & $1.56(0.97$ to 2.51$)$ & 0.064 \\
\hline \multicolumn{3}{|l|}{ Troubles affecting area } \\
\hline Not very much at all & 1.00 & 0.056 \\
\hline Just a little & $1.12(0.83$ to 1.51$)$ & 0.450 \\
\hline Quite a bit & 1.48 (1.07 to 2.05$)$ & 0.017 \\
\hline A lot & $1.57(0.98$ to 2.53$)$ & 0.059 \\
\hline
\end{tabular}

\section{Key points}

- The civil unrest (the Troubles) has persisted in Northern Ireland for more than 30 years and resulted in over 3600 deaths with thousands more injured or traumatised. However, the effects of the Troubles on the health of general population have not been well researched.

- In this study between one fifth and one quarter of respondents said the Troubles have had an important impact directly on their lives or on the areas in which they live.

- Exposure to the Troubles has resulted in a significant and independent detrimental effect on the mental health of the population of Northern Ireland.

- Whether or not this requires an additional input from the psychiatric services requires further research.

and those who were widowed or separated or divorced recorded higher GHQ scores. Those who had a long term illness, a disability, or a health stressor in the preceding year also had poorer psychological health and psychological morbidity was also inversely related to the levels of perceived social support. There was a clear gradient between the magnitude of the impact of the Troubles and the likelihood of having a high GHQ12 score though the effects of the Troubles on area just failed to reach conventional levels of statistical significance. As a check the final model was re-estimated using a cut off of 4 or more and the covariates and odd ratios were practical identical. Neither model showed significant second level interactions.

\section{DISCUSSION}

This study shows a positive and graded relation between the extent to which people and areas were affected by the Troubles in Northern Ireland and the likelihood of suffering from significant mental health problems. There were also some demographic and socioeconomic differences between those who reported effects of the Troubles on their area of residence and those who said that their lives, or the lives of their family had been affected by the Troubles. Others have noted the higher rates of Troubles related deaths in deprived areas, ${ }^{4}$ and these areas tend to have younger populations. Indeed most of the visible signs of the Troubles, such as the street rioting or knee cappings (where local residents are "punished" by being shot at close range (usually) in the knee) occur in working class areas, which are characterised by low incomes and public sector renting. By contrast those whose lives have been affected by the Troubles (including, for example, the members and families of the police and security forces) come from a wider range of geographical and socioeconomic backgrounds.

A possible caveat to this study must be that the measure of the effects of the Troubles was based on only two questions and that these were self reported estimates. There are however, no recognised and validated measures of the Troubles or agreement on how to equate and summate the deaths, injuries, punishment beatings, and knee cappings, or the associated criminality and intimidation. ${ }^{4}$ Previous research in Northern Ireland has shown that the appraisal of violence is not related to trait neuroticism ${ }^{20}$ - that the propensity to report exposure to violence is not influenced by premorbid personality. It could also be argued that if those with psychological morbidity were more likely to over-report what they considered as causative factors, they would also be more likely to emphasise their levels of self reported ill health, health stressors, and lack of social support, which in turn would have reduced the likelihood of the effects of the Troubles surviving in the regression analysis.

Is the higher level of psychological morbidity in Northern Ireland attributable in part to the effects of the Troubles? This study cannot definitively answer the question as it relates only to differences between people within Northern Ireland. It is possible that the poorer mental health is attributable to other features of Northern Ireland society. It is for example known that Northern Ireland is more impoverished than other parts of the $\mathrm{UK}^{21}$ and has poorer levels of physical health. ${ }^{2}$ However, we think that differences in mental health status between Northern Ireland and the rest of the UK cannot be explained in the main by these factors as this analysis showed that although the effects of the Troubles were more prevalent among those who were, on average, less affluent and in poorer health, controlling for these factors in the regression analysis did not greatly reduce the association between the Troubles and mental health. This suggests that the Troubles are a separate and additional burden and therefore contributes significantly to the higher psychological morbidity in Northern Ireland. The lower level of psychological morbidity in the Republic of Ireland has been confirmed using the GHQ12 (Layte R, personal communication) and South Eastern Health Board $^{22}$ and the SF $12 .{ }^{23}$ Why they are only about half the levels of those in the UK remains unknown though may be related to the feel good factor associated with the booming economy of the "Celtic tiger". ${ }^{24}$

In 1988 a review of the literature relating to the possible effects of the Troubles on mental health concluded that the campaign of terrorist violence had not seemed to have resulted in any obvious increase in psychiatric morbidity as measured by hospital admission levels, suicides and parasuicide levels, and levels of psychoactive drug prescriptions. ${ }^{25}$ It is however possible that the levels of psychological morbidity were generally increased without an apparent increase in the use of health services or change in trends in national mortality statistics. Many of the indicators of mental health that are largely based on contact with the caring professions will underestimate the impact of the Troubles if there has been significant denial or under reporting of symptoms and there is some evidence to suggest that most people in Northern Ireland deal with the stress generated by the political violence by denying the existence of the violence around them. ${ }^{26}$ In this study the higher levels of psychological morbidity of people who say that their lives are largely unaffected by the Troubles but who live in areas affected by the Troubles would tend to bear this out. A parallel could be drawn with physical health, which also tends to be poorer in areas associated with political violence, though studies have failed to show an association between levels of political violence and uptake of relevant services. ${ }^{27}$ 
The understanding of post-traumatic stress neurosis ${ }^{28}$ has significantly expanded since the 1988 review and it is now known that it may not be well recognised in the clinical setting ${ }^{29}{ }^{30}$ and therefore under-diagnosed and undertreated. ${ }^{31}$ This seems to be true even when doctors themselves are affected, for a quarter of doctors helping the victims of the Omagh bombing in August 1998 (in which 29 people were killed $^{5}$ ), exhibited symptoms of chronic post-traumatic stress but only one half of these had sought any help. ${ }^{32}$

An alternative suggestion is that the Troubles have resulted in higher levels of milder psychological disturbance (that has been called "normal anxiety" ${ }^{\text {") }}$ but have left the levels of more severe conditions largely unaffected. ${ }^{33}$ The psychiatric services are unclear how much additional input, if any, is required to meet these higher levels of psychological morbidity. ${ }^{28}$

This study does not provide an insight as to which aspects of the Troubles are having an impact on people's mental health. It may not be the more overt violence in itself that has caused the additional psychological morbidity. In recent years the level and character of violence has changed considerably so fewer people should be directly touched by it. 1997, the year in which the survey was conducted, was an unsettled time for the people of Northern Ireland. In the previous year the IRA (Irish Republican Army) had ended its two year cease fire and despite the 21 Troubles related deaths that occurred in 1997 there was a sense of optimism, of progress towards permanent peace. ${ }^{5}$ Yet a large proportion of the population in this survey said their lives had been affected by the Troubles. This might represent the cumulative effects of exposure to violence over the past 30 years, but it may also be attributable to other more indirect psychological stressors arising from the Troubles such as the ghetto mentality, intimidation, constitutional ambiguity or sectarianism, ${ }^{25}$ which are now prevalent in parts of Northern Ireland.

There is now increasing recognition that violence and the fear of violence is a public health issue ${ }^{34}$ and that its effects are much more widespread and pervasive than suggested by the official crime statistics. For example, in the US it has been suggested that the psychosocial costs of firearm violence are enormously higher than those associated with lost production or medical treatment. ${ }^{35}$ Violence, accompanied by greater delinquency, may also result in increased social disorganisation, a growing mistrust and an erosion of social capital in communities $^{36}$ that will further predispose people to psychological stress. ${ }^{37}$ There is some evidence that this has happened in Northern Ireland as it is now an extremely polarised society where more than two thirds of the population live in areas with more than $80 \%$ of one religion. ${ }^{21}$ Spatially segregated societies like this tend to have a disrupted psychology of place $^{38}$ and this can cause a sense of alienation and eventually anger and resentment, leading to confrontational interaction and further violence.

It will be interesting to see if the higher levels of psychiatric morbidity in Northern Ireland fall with time and an (hopefully) improving political situation. However, the experience of other countries ${ }^{39} 40$ suggests that resolving mental health issues in communities affected by years of violence and displacement will necessitate more than a cessation of violence and may also require an active process of reconciliation to promote social cohesion.

\section{Authors' affiliations}

D O'Reilly, M Stevenson, Department of Epidemiology and Public Health, The Queen's University of Belfast, Northern Ireland

Funding: none.

Conflicts of interest: none.

\section{REFERENCES}

1 Goldberg D, Williams PA. Users guide to the General Health

Questionnaire. Windsor: NFER-Nelson, 1988.
2 O'Reilly D, Browne S. Health and health services use in Northern Ireland: social variations report to the Department of Health, Social Services and Public Safety. Belfast: DHSSPS(NI), 2001.

3 Barry M, Friel S, Dempsey C, et al. Promoting mental health and social well-being: cross border opportunities and challenges. Armagh: Centre for Cross Border Studies, 2002

4 Fay MT, Morrisey M, Smyth M. Mapping troubles-related deaths in Northern Ireland 1969-1998. Initiative on conflict resolution and ethnicity. Belfast: University of Ulster, 1997.

5 McKittrick D, Kelters S, Feeney B, et al. Lost lives. Edinburgh: Mainstream Publishing, 1999.

6 Froggatt P. Medicine in Ulster in relation to the great famine and "the troubles". BM 1999;19:1636-9.

7 Fraser $\mathbf{R}$. The cost of commotion: an analysis of the psychiatric sequelae of the 1969 riots. Br J Psychiatry 1971;1 18:257-64.

8 Lyons $\mathbf{H}$. Psychiatric sequalae of the Belfast riots. Br J Psychiatry 1971;1 18:165-73.

9 Cairns E. Children and political violence. Oxford: Blackwell, 1996.

10 Bell P, Kee M, Loughery R, et al. Post traumatic stress in Northern Ireland. Acta Psychiatr Scand 1988:7:166-9.

11 Curran P, Bell P, Murray A, et al. Psychological consequences of the Enniskillen bombing. Br J Psychiatry 1990;156:479-82.

12 Donnelly M. Depression amongst adolescents in Northern Ireland. Adolescence 1995;30:339-50.

13 Donnelly M. Factors associated with depressed mood amongst adolescents in Northern Ireland. J Community Appl Soc Psychol 1999:9:47-59.

14 Scotland's Health. Scottish health survey 1995 Vol 1. Edinburgh: The Stationery Office, 1997

15 Prescott-Clarke, Primatesta P, eds. Health survey for England 1995. Vol 1: findings. London: UCL Medical School, 1997.

16 Campbell R, Stevenson G. Community differentials in health in Northern Ireland. Report to the Northern Ireland Department of Health and Social Services. Belfast: The Queen's University of Belfast, 1993.

17 O'Reilly D, Stevenson M. The two communities in Northern Ireland: deprivation and health. J Public Health Med 1998;20:161-8.

18 Davies H, Joshi H, Clarke L. Is it cash the deprived are short of? J R Stat Soc 1997; 160:107-26.

19 Blaxter M. Health and Lifestyles. London: Routledge, 1990

20 Cairns E, Wilson R. Coping with political violence in Northern Ireland. Soc Soc Med 1989;28:621-4.

21 Northern Ireland Statistics and Research Agency, Focus on Northern Ireland: a statistical profile. London: The Stationery Office, 1997.

22 South Eastern Health Board. The health of the South East. Report of the Director of Public Health. SEHB, 2002.

23 Layte R, Jenkinson C. Normative data for the SF-12 health survey in the Republic of Ireland with comparisons to England. Ir J Psychol 2001;21:63-72.

24 Bradley J. The Irish economy in perspective. In Nolan B, O'Connell P, Whelan C, eds. Bust to boom? The Irish experience of growth and inequality. Dublin: Institute of Public Administration, 2000:4-26.

25 Curran P. Psychiatric aspects of terrorist violence: Northern Ireland 1969-1987. Br J Psychiatry 1988;153:470-5.

26 Cairns $\mathrm{E}$, Wilson $\mathrm{R}$. The impact of political violence on mild psychiatric morbidity in Northern Ireland 1969-1987. Br J Psychiatry 1984; 145:631-5

27 Cairns E, Wilson R. Northern Ireland: political violence and self-reported physical symptoms in a community sample. J Psychosom Res 1991;35:707-11.

28 Daly O. Northern Ireland: the victims. Br J Psychiatry 1999;175:201-4

29 Gulbrandsen P, Hjortdahl P, Fugelli P. General practitioners' knowledge of their patients' psychosocial problems: multipractice questionnaire survey. BM 1997;314:1014.

30 van den Akker M, Mol S, Metsemakers J, et al. Barriers in the care of patients who have experienced a traumatic event: the perspective of general practice. Fam Pract $2001 ; 18: 214-16$.

31 Daly O. Doctors knowledge of post traumatic neurosis. Ulster Med J 1997;66:28-33

32 Firth-Crozen J, Midgley S, Burges C. Questionnaire survey of post-traumatic stress disorder in doctors involved in the Omagh bombing. BM 1999:319:1609

33 Cairns E, Wilson. Psychiatric aspects of violence in Northern Ireland. Stress Med 1985;1:193-201.

34 Middleton J. Crime is a public health problem. Med Confl Surviv 1998; 1:24-8.

35 Cook R, Ludwig J. Gun violence: the real costs. New York: Oxford University Press, 2000.

36 Galea S, Karpati, Kennedy B. Social capital and violence in the United States, 1973-1993. Soc Soc Med 2002;55:1373-83.

37 Silver E, Mulvey E, Swanson J. Neighborhood characteristics and mental disorder: Faris and Dunham revisited. Soc Soc Med 2002;55: 1457-70.

38 Fullilove $\mathbf{M}$. Psychiatric implications of displacement: contributions from the psychology of place. Am J Psychiatry 1996;153:1516-23.

39 Heon-Klin V. The influence of geopolitical change on the well-being of a population: The Berlin Wall. Am J Public Health 2001;91:369-405.

40 Miranda J, Vichez E. So simple and so meaningful: an approach to mental health after violence. J Epidemiol Community Health 2002;56:642. 